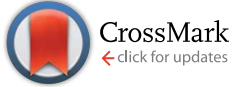

Cite this: RSC Adv., 2017, 7, 6187

Received 5th December 2016 Accepted 9th January 2017

DOI: 10.1039/c6ra27771c

www.rsc.org/advances

\section{Photoreductive synthesis of monodispersed Au nanoparticles with citric acid as reductant and surface stabilizing reagent $\dagger$}

\author{
Yasuhiro Shiraishi, ${ }^{\star a b}$ Haruki Tanaka, ${ }^{a}$ Hirokatsu Sakamoto, ${ }^{a}$ Satoshi Ichikawa ${ }^{c}$ \\ and Takayuki Hirai ${ }^{a}$
}

Colloidal suspensions of gold nanoparticles (AuNPs) in water can be prepared by heating water containing $\mathrm{HAuCl}_{4}$ with citric acid as reductant and surface stabilizing reagent. This thermal reduction method, however, promotes aggregation of the formed AuNPs, resulting in bimodal distribution of AuNPs. Here we report that UV (254 nm) irradiation of water containing $\mathrm{HAuCl}_{4}$ with citric acid at room temperature successfully reduces $\mathrm{HAuCl}_{4}$ and produces monodispersed AuNPs, while suppressing aggregation of the formed AuNPs. Changing the intensity of UV light or the amount of citric acid added successfully produces AuNPs with tunable sizes and narrow size distributions.

\section{Introduction}

Gold nanoparticles (AuNPs) have attracted much attention due to their unique optical, ${ }^{1}$ electronic, ${ }^{2}$ and chemical properties ${ }^{3}$ that differ significantly from those of bulk Au. Of particular interest is focused on application to cancer diagnosis, therapy, and bioimaging because of their localized surface plasmon resonance (LSPR) enhanced light scattering and absorption properties. ${ }^{4}$ In addition, due to the high surface-to-volume ratio, high surface energy, and strong LSPR absorption in the visible wavelength region, AuNPs often exhibit unusual catalytic, ${ }^{5}$ photocatalytic, ${ }^{6,7}$ or electronic properties. $^{8}$ These properties strongly depend on the size and dispersibility of AuNPs. ${ }^{9}$ Preparation of monodispersed AuNPs and their accurate size control, therefore, poses a challenge for advanced processing.

Thermal reduction of $\mathrm{Au}^{3+}$ is a common approach for the preparation of colloidal suspension of AuNPs. Ascorbic acid ${ }^{\mathbf{1 0}}$ and $\mathrm{NaBH}_{4}{ }^{11-13}$ have often been used as a reductant, but these methods need surface stabilizing reagent. Thermal reduction with trisodium citrate, the so-called Turkevich method, ${ }^{\mathbf{1 4 - 1 9}}$ is the simplest and most popular procedure for the preparation of AuNPs in water because trisodium citrate act as both reductant and surface stabilizing reagent. The $\mathrm{Na}^{+}$cations in the molecule, however, contaminate the formed AuNPs. ${ }^{20}$ The use of

\footnotetext{
${ }^{a}$ Research Center for Solar Energy Chemistry and Division of Chemical Engineering, Graduate School of Engineering Science, Osaka University, Toyonaka 560-8531, Japan.E-mail: shiraish@cheng.es.osaka-u.ac.jp

${ }^{b}$ Precursory Research for Embryonic Science and Technology (PRESTO), Japan Science and Technology Agency (JST), Saitama 332-0012, Japan

${ }^{c}$ Institute for NanoScience Design, Osaka University, Toyonaka 560-8531, Japan

$\dagger$ Electronic supplementary information (ESI) available: Supplementary data (Fig. S1-S6). See DOI: 10.1039/c6ra27771c
}

metal-free reductant is therefore necessary. Citric acid is one potential reductant for this purpose: ${ }^{21}$ simple stirring of water containing $\mathrm{HAuCl}_{4}$ with citric acid at elevated temperature successfully produces AuNPs. This method, however, inevitably promotes thermal aggregation of the formed AuNPs due to the weak adsorption of citric acid onto the AuNPs surface. ${ }^{21}$ Reduction of $\mathrm{HAuCl}_{4}$ at relatively low temperature is therefore necessary for the preparation of monodispersed AuNPs.

Recently, photoreduction of $\mathrm{Au}^{3+}$ has also received much attention as an alternative method for AuNPs synthesis because it can be operated at room temperature by UV irradiation. Many of the reported photoreduction methods need both reductants and surface stabilizing reagents. ${ }^{22-29}$ Although some systems can use single chemicals behaving as both reductant and surface stabilizing reagent such as ionic liquids, dendrimers, polyvinylpyrrolidone, and trisodium citrate, they are relatively expensive or contain $\mathrm{Na}^{+}$cation contaminant. ${ }^{30-33}$ Yang et al. ${ }^{34}$ used citric acid for photoreductive synthesis of AuNPs. They found that UV irradiation of water containing $\mathrm{HAuCl}_{4}$ and citric acid successfully reduces $\mathrm{Au}^{3+}$ and produces AuNPs. They also studied the $\mathrm{pH}$ effects on the rate of AuNPs formation by UV-vis absorption spectroscopy and the size of AuNPs by transmission electron microscopy (TEM) observations, but did not clarify the dispersibility of the formed AuNPs.

In the present work, we studied photoreductive synthesis of AuNPs in pure water with citric acid by UV $(254 \mathrm{~nm})$ irradiation at room temperature. The size and dispersibility of AuNPs were studied by TEM and dynamic laser scattering (DLS) analysis and were compared with those obtained by thermal reduction. We found that this photoreduction method successfully produces monodispersed AuNPs, while suppressing subsequent aggregation of the formed AuNPs. We also report here that changing the intensity of UV light and the amount of citric acid 
successfully produces monodispersed AuNPs with tunable sizes and narrow size distributions.

\section{Results and discussion}

\section{Thermal reduction}

AuNPs were prepared with citric acid by conventional thermal reduction method. A water $(2 \mathrm{~mL})$ containing $\mathrm{HAuCl}_{4} \cdot 4 \mathrm{H}_{2} \mathrm{O}(0.2$ $\mathrm{mM})$ and citric acid $(0.5 \mathrm{mM})$ was stirred at $60^{\circ} \mathrm{C}$ in a quartz cell within a Peltier temperature controller. Fig. 1a shows timedependent change in absorption spectra of the solution. A distinctive LSPR band of AuNPs appears at $534 \mathrm{~nm}$ and increases with time. Simultaneously, red-shifted absorption band at $\lambda>$ $600 \mathrm{~nm}$, assigned to interparticle-coupled plasmon excitons of aggregated AuNPs, increases. ${ }^{35}$ This suggests that AuNPs formed by thermal reduction of $\mathrm{HAuCl}_{4}$ are subsequently aggregated. ${ }^{21,36}$ It is noted that the obtained solution maintain its transparency at least 2 days, where a precipitate formation scarcely occurs. Fig. 1b (blue) shows hydrodynamic diameter of AuNPs prepared at $60{ }^{\circ} \mathrm{C}$ by 25 min stirring, measured by DLS analysis. Bimodal particle distributions with average diameters $c a .40 \mathrm{~nm}$ and $150 \mathrm{~nm}$ were observed. This indicates that ca. $40 \mathrm{~nm}$ AuNPs formed by thermal reduction of $\mathrm{HAuCl}_{4}$ are subsequently aggregated and produce $c a .150 \mathrm{~nm}$ aggregates. Fig. 1c shows typical TEM images of the particles. The TEM samples were prepared by dipping a microgrid into the solution $(2 \mathrm{~s})$ followed by drying under air (10 s) and in vacuo (30 min). The sizes of AuNPs and their aggregates are $c a .40 \mathrm{~nm}$ and $150 \mathrm{~nm}$, respectively, which agree with the DLS results (Fig. 1b).
Thermal reduction of $\mathrm{HAuCl}_{4}$ was performed at $90{ }^{\circ} \mathrm{C}, 40{ }^{\circ} \mathrm{C}$, and $25{ }^{\circ} \mathrm{C}$, respectively. As shown in Fig. S1 (ESI $\dagger$ ), stirring at $90{ }^{\circ} \mathrm{C}$ and $40{ }^{\circ} \mathrm{C}$ shows LSPR band of AuNPs as well as redshifted band of the aggregates, as is the case at $60{ }^{\circ} \mathrm{C}$ (Fig. 1a). In addition, as shown in Fig. 1b, DLS analysis of these solutions also shows bimodal particle distributions, indicating that AuNPs undergo thermal aggregation even at $40{ }^{\circ} \mathrm{C}$. However, as shown in Fig. S1 (ESI $\dagger$ ), stirring at $25{ }^{\circ} \mathrm{C}$ scarcely increases the LSPR band. As shown in Fig. 1d (black), LSPR absorbance scarcely increases even after 30 min stirring, indicating that $\mathrm{HAuCl}_{4}$ is not reduced at $25{ }^{\circ} \mathrm{C}$. These data indicate that the thermal reduction method is difficult to prepare monodispersed AuNPs while suppressing subsequent their aggregation.

\section{Photoreduction}

AuNPs were prepared by the photoreduction method. Water (2 $\mathrm{mL})$ containing $\mathrm{HAuCl}_{4} \cdot 4 \mathrm{H}_{2} \mathrm{O}(0.2 \mathrm{mM})$ and citric acid $(0.5 \mathrm{mM})$ was stirred at $25{ }^{\circ} \mathrm{C}$ under irradiation of $254 \mathrm{~nm}$ light by a Xe lamp (light intensity: $150 \mathrm{~mW} \mathrm{~m}^{-2}$ ). Fig. $2 \mathrm{a}$ shows the timedependent change in absorption spectra of the solution. As is the case for thermal reduction (Fig. 1a), LSPR absorption of AuNPs appears at $530 \mathrm{~nm}$ and increases with irradiation time. In this case, red-shifted absorption scarcely appears, indicating that the formed AuNPs scarcely aggregate. It must also be noted that the obtained solution maintain its transparency at least 2 days, where a precipitate formation scarcely occurs, as is the case for the thermal reduction. As shown in Fig. 2b, DLS
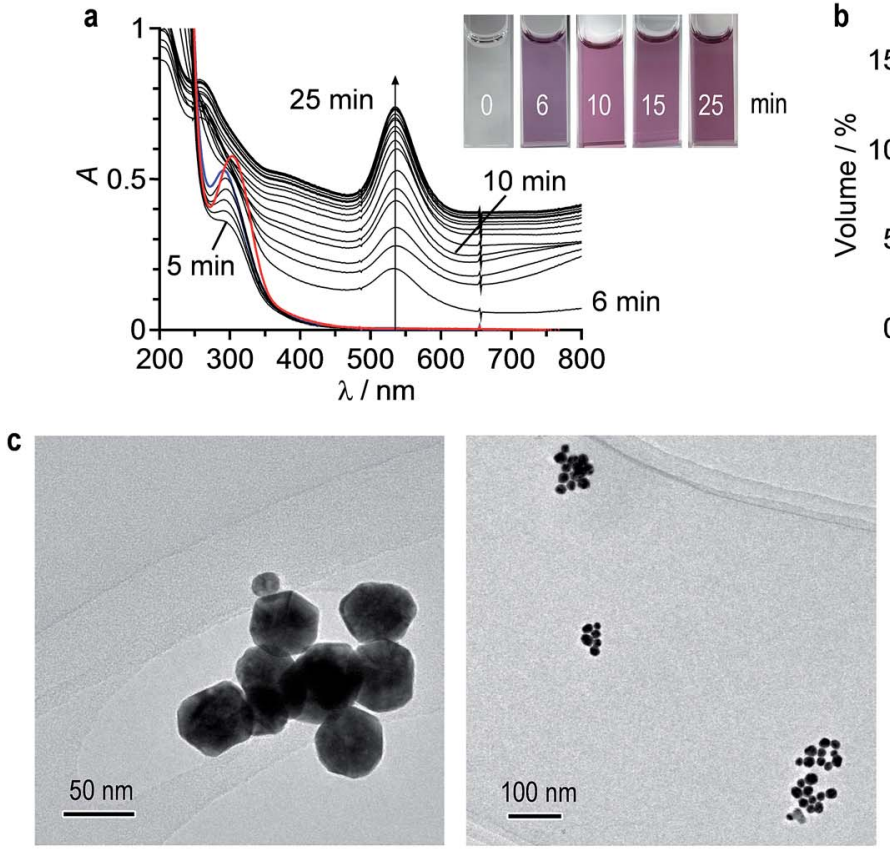

Fig. 1 (a) Time-dependent change in absorption spectra of water containing $\mathrm{HAuCl}_{4} \cdot 4 \mathrm{H}_{2} \mathrm{O}(0.2 \mathrm{mM})$ and citric acid $(0.5 \mathrm{mM})$ during stirring at $60{ }^{\circ} \mathrm{C}$ in the dark. The red is the spectrum for the solution containing $\mathrm{HAuCl}_{4} \cdot 4 \mathrm{H}_{2} \mathrm{O}$ at $25^{\circ} \mathrm{C}$, and the blue is the spectrum for the solution after addition of citric acid $(1 \mathrm{~min})$. (b) Hydrodynamic diameter of the solution obtained by stirring in the dark at $90^{\circ} \mathrm{C}(10 \mathrm{~min}), 60^{\circ} \mathrm{C}(25 \mathrm{~min}), 40{ }^{\circ} \mathrm{C}$ (30 min), and $25^{\circ} \mathrm{C}$ (30 min), measured by DLS analysis. (c) Typical TEM images of the solution obtained by $25 \mathrm{~min}$ stirring at $60^{\circ} \mathrm{C}$ in the dark. (d) Time-dependent change in the LSPR absorbance of the solutions during stirring at different temperatures in the dark. 

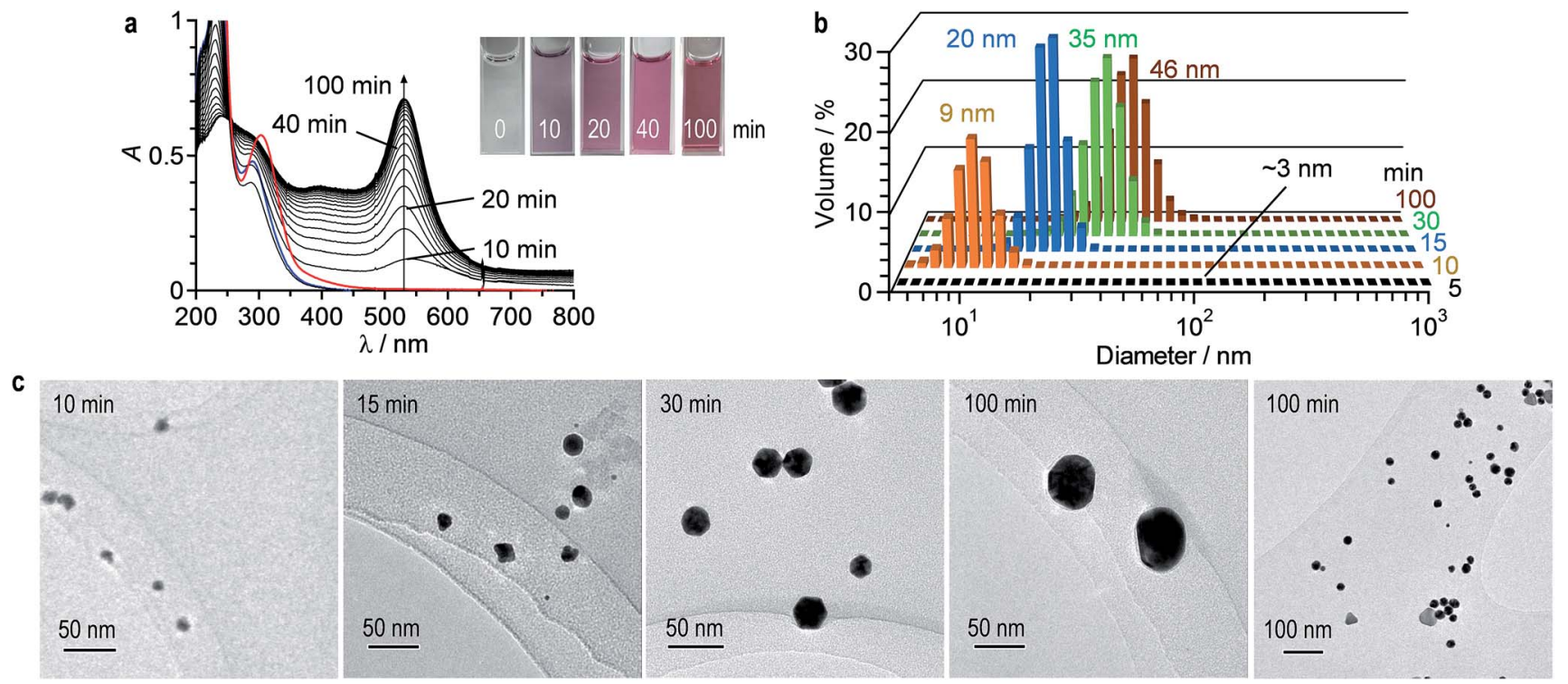

Fig. 2 (a) Time-dependent change in absorption spectra of water containing $\mathrm{HAuCl}_{4} \cdot 4 \mathrm{H}_{2} \mathrm{O}(0.2 \mathrm{mM})$ and citric acid (0.5 mM) during stirring at $25^{\circ} \mathrm{C}$ under $254 \mathrm{~nm}$ irradiation (light intensity: $150 \mathrm{~mW} \mathrm{~m}^{-2}$ ). The red is the spectrum of a solution containing $\mathrm{HAuCl}_{4} \cdot 4 \mathrm{H}_{2} \mathrm{O}$ at $25{ }^{\circ} \mathrm{C}$, and the blue is the spectrum for the solution after addition of citric acid (1 min). (b) Hydrodynamic diameter and (c) TEM images of AuNPs obtained after different photoirradiation time.

analysis shows unimodal distribution of AuNPs with an average diameter $c a .50 \mathrm{~nm}$, where aggregated AuNPs are scarcely observed. This suggests that photoreduction method scarcely promotes aggregation of the formed AuNPs. TEM observations confirm this. As show in Fig. 2c (right side), the TEM images obtained by $100 \mathrm{~min}$ stirring of the solution show welldispersed $c a .50 \mathrm{~nm}$ AuNPs, where large aggregates are scarcely formed. As shown in Fig. S2 (ESI†), X-ray photoelectron spectroscopy (XPS) analysis of the AuNPs prepared by both thermal- and photoreduction methods exhibits characteristic $\mathrm{Au} 4 \mathrm{f} 5 / 2$ and $4 \mathrm{f} 7 / 2$ peaks at $c a .84 .3$ and $88.0 \mathrm{eV}$, respectively, assigned to $\mathrm{Au}^{0}$. In that, a component assigned to $\mathrm{Au}^{3+} \mathrm{Or} \mathrm{Au}^{+}$is scarcely observed at $85-86 \mathrm{eV},,^{37,38}$ indicating that these cations are not contained in the obtained AuNPs.

\section{Mechanism for AuNPs formation by thermal reduction}

It is well known that thermal reduction creates AuNPs by the nucleation and growth processes. ${ }^{34}$ As shown in Scheme 1, coordination of citric acid with $\mathrm{Au}^{3+} \mathrm{Cl}_{4}{ }^{-}$produces a citrate$\mathrm{Au}^{3+} \mathrm{Cl}_{3}{ }^{-}$complex. ${ }^{14}$ Absorption spectra confirm this. As shown by the red line in Fig. 1a, the ligand-to-metal charge transfer (LMCT) band of $\mathrm{AuCl}_{4}{ }^{-}$appears at $303 \mathrm{~nm} \cdot{ }^{39}$ As shown by the blue line, addition of citric acid to this solution rapidly leads to blue shift of this band to $290 \mathrm{~nm}$ within $1 \mathrm{~min}$ due to the formation of a citrate- $\mathrm{Au}^{3+} \mathrm{Cl}_{3}{ }^{-}$complex. ${ }^{14}$ Heating the solution at $60^{\circ} \mathrm{C}$ decreases this band, along with an increase in the LSPR band of AuNPs. This indicates that, as shown in Scheme 1, thermal activation of the citrate- $\mathrm{Au}^{3+} \mathrm{Cl}_{3}{ }^{-}$produces a reduced $\mathrm{Au}^{2+} \mathrm{Cl}_{n}{ }^{m-}$ species, along with a formation of oxidation products of citric acid such as dicarboxyacetone, acetoacetate, and $\mathrm{CO}_{2}{ }^{40-44}$ Subsequent reduction of the formed citrate- $\mathrm{Au}^{2+} \mathrm{Cl}_{n}{ }^{m-}$ complex followed by the reduction of citrate- $\mathrm{Au}^{+} \mathrm{Cl}_{n}{ }^{m-}$ complex produce $\mathrm{Au}^{0}$, resulting in the formation of $\mathrm{Au}^{0}$ nuclei. Further adsorption of $\mathrm{Au}^{0}$ onto the nuclei leads to a growth of AuNPs. ${ }^{34}$ In that, the citrate anions are adsorbed onto the AuNPs surface and behave as a surface stabilizing reagent. ${ }^{45}$ Negative charge of these surface anions suppresses aggregation of AuNPs due to
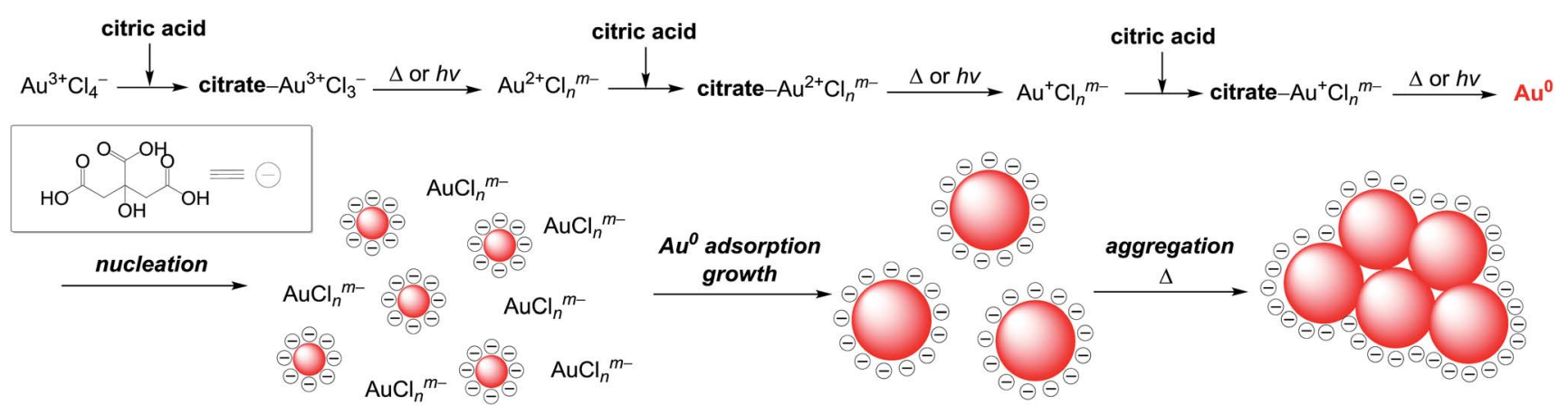

Scheme 1 Mechanism for the formation of AuNPs by thermal reduction and photoreduction methods. 
the electrostatic repulsion. ${ }^{46} \mathrm{~A}$ rise in temperature, however, weakens the adsorption of these anions, inevitably promoting aggregation of AuNPs.

\section{Mechanism for AuNPs formation by photoreduction}

In the photoreduction method, AuNPs are formed by the mechanism similar to that of thermal reduction (Scheme 1). As shown in Fig. 2a, UV irradiation of the citrate- $\mathrm{Au}^{3+} \mathrm{Cl}_{3}{ }^{-}$complex leads to a decrease in its LMCT band (blue line), along with a formation of LSPR absorption, as is the case for thermal reduction (Fig. 1a). GC analysis of the gas phase after $100 \mathrm{~min}$ photoirradiation detects the formation of $\mathrm{CO}_{2}$. The AuNPs in the solution were removed by centrifugation. The obtained solution was concentrated by evaporation and dissolved in DMSO- $d_{6}$. As shown in Fig. S3 (ESI $\dagger$ ), ${ }^{1} \mathrm{H}$ NMR analysis of the solution shows a formation of acetoacetate and dicarboxyacetone as the oxidation products of citric acid. These findings indicate that, as shown in Scheme 1 (top), consecutive photoexcitation of the citrate- $\mathrm{AuCl}_{n}{ }^{m-}$ complexes reduces $\mathrm{Au}^{3+}$ to $\mathrm{Au}^{0}$ with the oxidation of citric acid, as is the case for thermal activation. ${ }^{\mathbf{4 0 - 4 4}}$ Similar mechanism has been proposed in the photoreduction of some metal cations such as $\mathrm{Ag}^{+}$and $\mathrm{Fe}^{3+}$ with citric acid by UV irradiation. ${ }^{47,48}$

As shown in Scheme 1 (bottom), the formation of $\mathrm{Au}^{0}$ nuclei and their growth produce AuNPs, as is the case for thermal reduction. As shown in Fig. 2a, photoirradiation for $5 \mathrm{~min}$ scarcely leads to an increase in the LSPR absorption, where AuNPs are scarcely observed by DLS analysis (Fig. 2b; detection limit: $3 \mathrm{~nm}$ ). Photoirradiation for $10 \mathrm{~min}$ creates a LSPR band, where small ( 10 nm) AuNPs are observed by DLS (Fig. 2b) and TEM (Fig. 2c, left). Further photoirradiation creates larger AuNPs; DLS and TEM confirm the growth of AuNPs. These data suggest that, as shown in Scheme 1, the photoreduction method produces AuNPs via the nucleation and growth mechanism in a manner similar to that of thermal reduction. Photoirradiation for $100 \mathrm{~min}$ finally produces ca. $50 \mathrm{~nm}$ AuNPs. At this temperature $\left(25{ }^{\circ} \mathrm{C}\right)$, the adsorbed citric acid molecules sufficiently stabilize the particles and suppress their aggregation, resulting in the formation of monodispersed AuNPs.

\section{Size control of AuNPs by photoreduction}

It is well known that, in the thermal reduction, the size of AuNPs depends strongly on the rate of $\mathrm{AuCl}_{n}{ }^{m-}$ reduction. ${ }^{49}$ Increased rate of $\mathrm{AuCl}_{n}{ }^{m-}$ reduction creates a large number of $\mathrm{Au}^{0}$ nuclei and decreases the number of $\mathrm{AuCl}_{n}{ }^{m-}$ remaining in solution. This suppresses the growth of the particles and creates smaller AuNPs. As shown in Fig. 1d, stirring of a $\mathrm{HAuCl}_{4}$ solution with citric acid at higher temperature accelerates the increase in the LSPR absorption. In addition, as shown in Fig. 1b, the size of AuNPs becomes smaller at higher temperature. This is because, at higher temperature, enhanced reduction of $\mathrm{AuCl}_{n}{ }^{m-}$ creates larger number of $\mathrm{Au}^{0}$ nuclei and produces smaller AuNPs. ${ }^{50}$

In the photoreduction, the rate of $\mathrm{AuCl}_{n}{ }^{m-}$ reduction can be controlled by the intensity of UV light and the amount of citric acid. Fig. 3a shows effect of the light intensity on the time-

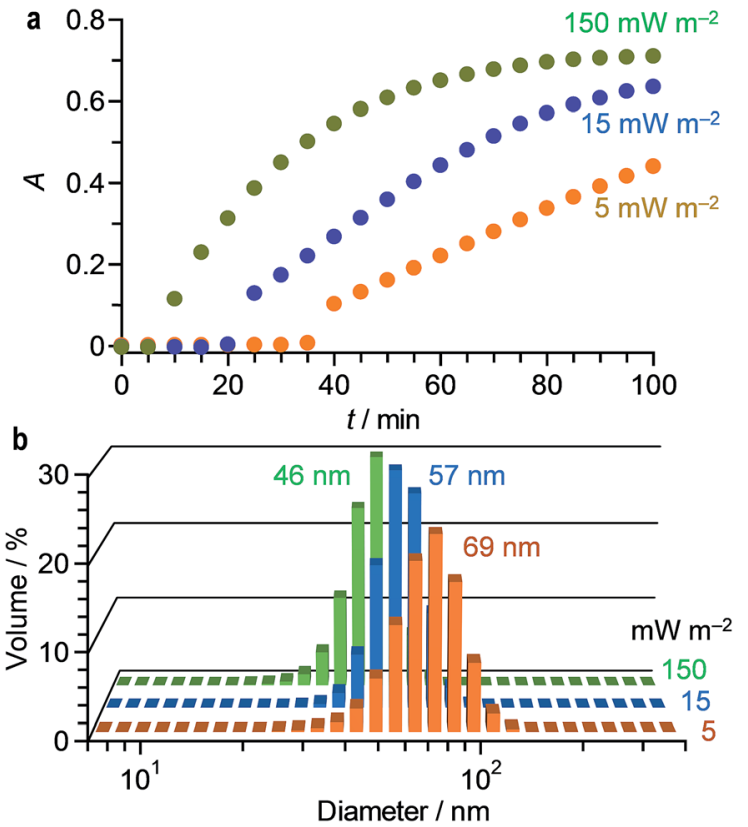

Fig. 3 (a) Time-dependent change in the LSPR absorbance of water containing $\mathrm{HAuCl}_{4} \cdot 4 \mathrm{H}_{2} \mathrm{O}(0.2 \mathrm{mM})$ and citric acid $(0.5 \mathrm{mM})$ during stirring at $25{ }^{\circ} \mathrm{C}$ under $254 \mathrm{~nm}$ irradiation at different light intensity. Changes in absorption spectra are summarized in Fig. S4 (ESI†). (b) Hydrodynamic diameter of AuNPs measured by DLS analysis after photoirradiation at different light intensity for $100 \mathrm{~min}$.

dependent change in the LSPR absorbance of the solution. The increased light intensity increases the absorbance more rapidly because it enhances photoexcitation of the citrate$\mathrm{AuCl}_{n}{ }^{m-}$ complexes and promotes rapid reduction to $\mathrm{Au}^{0}$. Fig. 3b shows the size of AuNPs prepared at different light intensity. The increased light intensity indeed creates smaller AuNPs, where their aggregation does not occur. In this case, monodispersed 50-70 nm AuNPs can be created while maintaining narrow size distribution with $<23 \%$ standard deviation.

It is also noted that the rate of photoreduction depends on the wavelength of incident light; UV irradiation is necessary. As shown in Fig. S6 (ESI $\dagger$ ), the rate of LSPR absorption increase decreases by photoexcitation with longer wavelength light (254 $>360>510 \mathrm{~nm}$ ), where the photoexcitation by $510 \mathrm{~nm}$ light scarcely increases the LSPR absorbance. This is because, as shown by the blue line in Fig. 2a, the absorbance of the citrate$\mathrm{AuCl}_{n}{ }^{m-}$ complexes decreases at longer wavelengths and scarcely absorbs light in the visible region.

Fig. 4a shows effect of the citric acid amount on the timedependent change in the LSPR absorbance of the solution. The increased amount of citric acid rapidly increases the LSPR absorbance because it produces a larger number of citrate$\mathrm{AuCl}_{n}{ }^{m-}$ complexes and promotes rapid formation of larger number of $\mathrm{Au}^{0}$ nuclei. Therefore, as shown in Fig. $4 \mathrm{~b}$ and $\mathrm{c}$, the increased amount of citric acid produces smaller AuNPs, where their aggregation does not occur. Changing the citric acid amount successfully creates monodispersed AuNPs with 22$70 \mathrm{~nm}$ diameters, while maintaining narrow size distribution with $<54 \%$ standard deviation. 


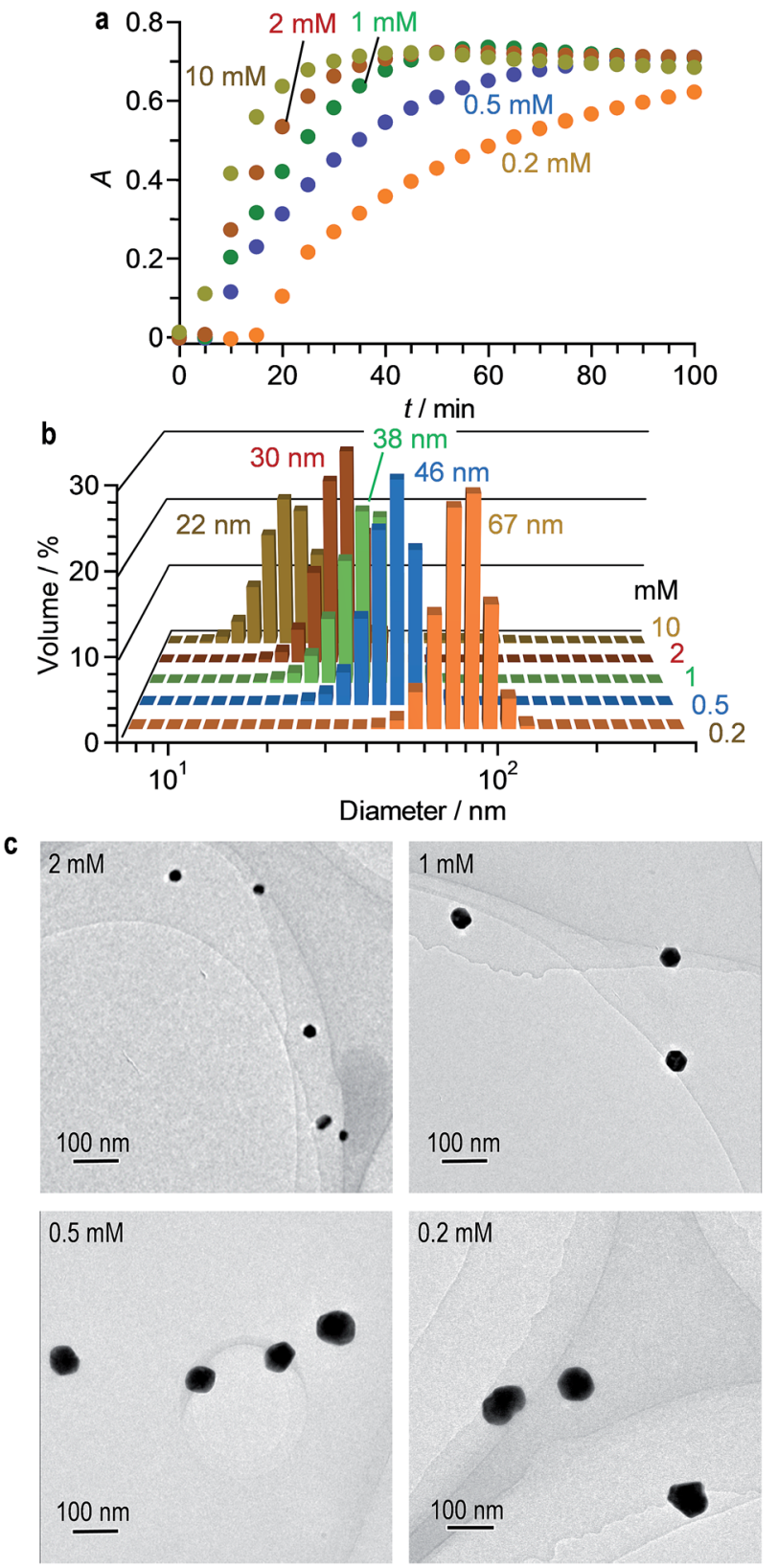

Fig. 4 (a) Time-dependent change in absorption spectra of water containing $\mathrm{HAuCl}_{4} \cdot 4 \mathrm{H}_{2} \mathrm{O}(0.2 \mathrm{mM})$ and different amount of citric acid during stirring at $25{ }^{\circ} \mathrm{C}$ under $254 \mathrm{~nm}$ irradiation (light intensity: 150 $\mathrm{mW} \mathrm{m}^{-2}$ ). Changes in absorption spectra are summarized in Fig. S5 (ESI†). (b) Hydrodynamic diameter and (c) TEM images of AuNPs obtained after photoirradiation for $100 \mathrm{~min}$ with different citric acid amount.

\section{Conclusion}

We found a simple method for preparation of monodispersed AuNPs. UV irradiation $(254 \mathrm{~nm})$ of water containing $\mathrm{HAuCl}_{4}$ and citric acid at room temperature successfully produces monodispersed AuNPs, while suppressing aggregation of the formed AuNPs. Changing the light intensity or the amount of citric acid successfully produces AuNPs with tunable sizes $(20-70 \mathrm{~nm})$ and narrow size distributions $(<54 \%$ standard deviation $)$. This simple but effective photo process may become one powerful method for the synthesis of monodispersed AuNPs. The results presented here may contribute to the design of simpler and more efficient method for metal nanoparticle processing.

\section{Experimental}

\section{Materials and methods}

All reagents were supplied from Wako and used without further purification. Water was purified by the Milli-Q system. Thermal reduction was performed as follows: water $(2 \mathrm{~mL})$ containing $\mathrm{HAuCl}_{4} \cdot 4 \mathrm{H}_{2} \mathrm{O}(0.2 \mathrm{mM})$ and citric acid $(0.5 \mathrm{mM})$ was stirred at the designated temperature in the dark. Photoreduction was carried out as follows: water $(2 \mathrm{~mL})$ containing $\mathrm{HAuCl}_{4} \cdot 4 \mathrm{H}_{2} \mathrm{O}$ $(0.2 \mathrm{mM})$ and required amount of citric acid was stirred at $25^{\circ} \mathrm{C}$ under $254 \mathrm{~nm}$ light irradiation. All reactions were performed on an UV-visible photodiode-array spectrophotometer (Shimadzu; Multispec-1500) equipped with a Peltier temperature controller (Shimadzu; S-1000) using a $10 \mathrm{~mm}$ path length quartz cell. The light irradiation was performed with a Xe lamp $(300 \mathrm{~W}$; Asahi Spectra Co. Ltd.; Max-302) equipped with 254, 360, or $510 \mathrm{~nm}$ band-pass filter. ${ }^{51}$ The full-width at half-maximum of the light (FWHM) was $12 \mathrm{~nm}$. The photon number entered into the reaction vessel was determined with a spectroradiometer (USR40 , USHIO Inc.). ${ }^{52}$

\section{Analysis}

${ }^{1}$ H NMR spectra were obtained on a JEOL JNM-AL400 Excalibur. Hydrodynamic diameter was measured on a dynamic laser scattering spectrometer (LB-500, HORIBA). TEM observations were performed on an FEI Tecnai G2 20ST analytical electron microscope $(200 \mathrm{kV}) .{ }^{53}$ XPS analysis was performed on a Kratos Axis Ultra spectrometer (Jasco Corp.). ${ }^{54}$

\section{Acknowledgements}

This work was supported by the Grant-in-Aid for Challenging Exploratory Research (No. 15K14203) from the Japan Society for the Promotion of Science (JSPS).

\section{Notes and references}

1 M. E. Stewart, C. R. Anderton, L. B. Thompson, J. Maria, S. K. Gray, J. A. Rogers and R. G. Nuzzo, Chem. Rev., 2008, 108, 494-521.

2 M. Grzelczak, J. Vermant, E. M. Furst and L. M. Liz-Marzán, ACS Nano, 2010, 4, 3591-3605.

3 M. C. Daniel and D. Astruc, Chem. Rev., 2004, 104, 293-346.

4 P. K. Jain, I. H. El-Sayed and M. A. El-Sayed, Nano Today, 2007, 2, 18-29.

5 B. Hvolbaek, T. V. W. Janssens, B. S. Clausen, H. Falsig, C. H. Christensen and J. K. Nørskov, Nano Today, 2007, 2, 14-18.

6 D. Tsukamoto, Y. Shiraishi, Y. Sugano, S. Ichikawa, S. Tanaka and T. Hirai, J. Am. Chem. Soc., 2012, 134, 63096315. 
7 Y. Sugano, Y. Shiraishi, D. Tsukamoto, S. Ichikawa, S. Tanaka and T. Hirai, Angew. Chem., Int. Ed., 2013, 52, 5295-5299.

8 D. I. Gittins, D. Bethell, D. J. Schiffrin and R. J. A. Nichols, Nature, 2000, 408, 67-69.

9 K. J. M. Bishop, C. E. Wilmer, S. Soh and B. A. Grzybowski, Small, 2009, 5, 1600-1630.

10 B. Xavier, A. Ramanand and P. Sagayaraj, Pharma Chem., 2012, 4, 1467-1470.

11 J.-W. Kim, J. H. Kim, S. J. Chung and B. H. Chung, Analyst, 2009, 134, 1291-1293.

12 S. H. Lee, K. H. Bae, S. H. Kim, K. R. Lee and T. G. Park, Int. J. Pharm., 2008, 364, 94-101.

13 N. Zhou, J. Wang, T. Chen, Z. Yu and G. Li, Anal. Chem., 2006, 78, 5227-5230.

14 J. Turkevich, P. C. Stevenson and J. Hillier, Discuss. Faraday Soc., 1951, 11, 55-75.

15 G. Frens, Nature (London), Phys. Sci., 1973, 241, 20-22.

16 J. Kimling, M. Maier, B. Okenve, V. Kotaidis, H. Ballot and A. Plech, J. Phys. Chem. B, 2006, 110, 15700-15707.

17 X. Ji, X. Song, J. Li, Y. Bai, W. Yang and X. Peng, J. Am. Chem. Soc., 2007, 129, 13939-13948.

18 A. A. Volkert, V. Subramaniam and A. J. Haes, Chem. Commun., 2011, 47, 478-480.

19 S. K. Sivaraman, S. Kumar and V. Santhanam, J. Colloid Interface Sci., 2011, 361, 543-547.

20 B. J. Luc and D. Bruno, Semicond. Sci. Technol., 2010, 57-78.

21 F. Shiba, CrystEngComm, 2013, 15, 8412-8415.

22 M. Harada and S. Kizaki, Cryst. Growth Des., 2016, 16, 12001212.

23 Y. Zhou, T. Ping, I. Maitlo, B. Wang, M. Y. Akram, J. Nie and X. Zhu, Nanotechnology, 2016, 27, 215301-215309.

24 Y. L. Jung, J. H. Park, M. I. Kim and H. G. Park, Nanotechnology, 2016, 27, 055501-055507.

25 H. Ma, D. Lin, H. Liu, L. Yang, L. Zhang and J. Liu, Mater. Chem. Phys., 2013, 138, 573-580.

26 F. H. Anka, S. D. Perera, C. Ratanatawanate and K. J. Balkus Jr, Mater. Lett., 2012, 75, 12-15.

27 F. B. Lollmahomed and R. Narain, Langmuir, 2011, 27, 12642-12649.

28 M. Harada and H. Einaga, Langmuir, 2007, 23, 6536-6543.

29 M. Y. Han and C. H. Quek, Langmuir, 2000, 16, 362-367.

30 Y. Nakazato, K. Taniguchi, S. Ono, T. Eitoku and K. Katayama, Phys. Chem. Chem. Phys., 2009, 11, 1006410072.

31 B. I. Zapadinskii, V. T. Shashkova, L. A. Pevtsova, A. V. Kotova, I. A. Matveeva and A. O. Stankevich, Polym. Sci., Ser. B, 2013, 55, 31-34.
32 K. Esumi, A. Suzuki, N. Aihara, K. Usui and K. Torigoe, Langmuir, 1998, 14, 3157-3159.

33 W.-E. Lu, M.-L. Zheng, W.-Q. Chen, Z.-S. Zhao and X.-M. Duan, Phys. Chem. Chem. Phys., 2012, 14, 11930-11936.

34 S. Yang, Y. Wang, Q. Wang, R. Zhang and B. Ding, Colloids Surf., A, 2007, 301, 174-183.

35 P. K. Jain, W. Huang and M. A. EI-Sayed, Nano Lett., 2007, 7, 2080-2088.

36 Y. Shiraishi, H. Tanaka, H. Sakamoto, S. Ichikawa and T. Hirai, RSC Adv., 2015, 5, 77572-77580.

37 D. C. Lim, R. Dietsche, G. Ganteför and Y. D. Kim, Appl. Surf. Sci., 2009, 256, 1148-1151.

38 Y. L. Mikhlin, A. S. Romanchenko and I. P. Asanov, Geochim. Cosmochim. Acta, 2006, 70, 4874-4888.

39 K. D. N. Vo, E. Guillon, L. Dupont, C. Kowandy and X. Coqueret, J. Phys. Chem. C, 2014, 118, 4465-4474.

40 I. Ojea-Jimenez, F. M. Romero, N. G. Bastus and V. Puntes, J. Phys. Chem. C, 2010, 114, 1800-1804.

41 B. Rodorígez-González, P. Mulvaney and L. M. Z. LizMarzán, J. Phys. Chem. A, 2007, 221, 415-426.

42 X. Wu, P. L. Redmond, H. Liu, Y. Chen, M. Steigerwald and L. Brus, J. Am. Chem. Soc., 2008, 130, 9500-9506.

43 C. H. Munro, W. E. Smith, M. Garner, J. Clarkson and P. C. White, Langmuir, 1995, 11, 3712-3720.

44 C. Xue, G. S. Metraux, J. E. Millstone and C. A. Mirkin, J. Am. Chem. Soc., 2008, 130, 8337-8344.

45 P. Zhao, N. Li and D. Astruc, Coord. Chem. Rev., 2013, 257, 638-665.

46 Y. Shiraishi, K. Tanaka, E. Shirakawa, Y. Sugano, S. Ichikawa, S. Tanaka and T. Hirai, Angew. Chem., Int. Ed., 2013, 52, 8304-8308.

47 X. Li, X. Mao, X. Zhang, Y. Wang, Y. Wang, H. Zhang, X. Hao and C. Fan, Sci. China: Chem., 2015, 58, 457-466.

48 N. Seraghni, S. Belattar, Y. Mameri, N. Debbache and T. Sehili, Int. J. Photoenergy, 2012, 630425, 1-10.

49 K. Okitsu, A. Yue, S. Tanaba, H. Matsumoto, Y. Yobiko and Y. Yoo, Bull. Chem. Soc. Jpn., 2002, 75, 2289-2296.

50 M. Tran, R. DePenning, M. Turner and S. Padalkar, Mater. Res. Express, 2016, 3, 105027-105036.

51 Y. Shiraishi, S. Sumiya and T. Hirai, Chem. Commun., 2011, 47, 4953-4955.

52 H. Koizumi, Y. Shiraishi, S. Tojo, M. Fujitsuka, T. Majima and T. Hirai, J. Am. Chem. Soc., 2006, 128, 8751-8753.

53 Y. Shiraishi, H. Sakamoto, Y. Sugano, S. Ichikawa and T. Hirai, ACS Nano, 2013, 7, 9287-9297.

54 Y. Kofuji, Y. Isobe, Y. Shiraishi, H. Sakamoto, S. Tanaka, S. Ichikawa and T. Hirai, J. Am. Chem. Soc., 2016, 138, 10019-10025. 